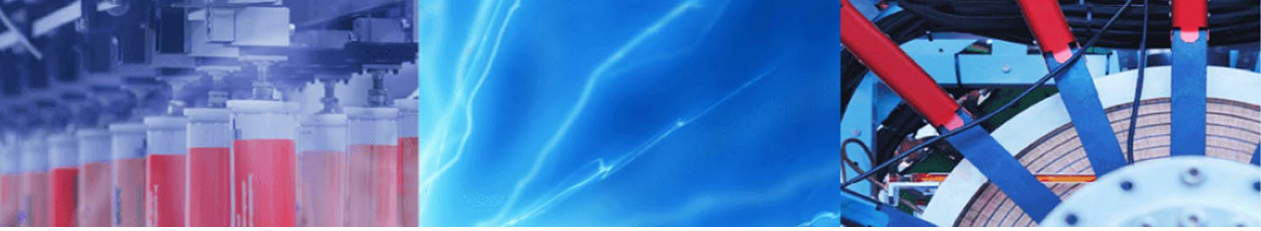

Research Article

\title{
Facile green synthesis of gold nanoparticles from marine algae Gelidiella acerosa and evaluation of its biological Potential
}

\author{
P. Senthilkumar ${ }^{1} \cdot$ L. Surendran ${ }^{1}$ · B. Sudhagar ${ }^{2}$ - D. S. Ranjith Santhosh Kumar ${ }^{3}$
}

(c) Springer Nature Switzerland AG 2019

\begin{abstract}
In this present research, the Gold nanoparticles (GA-AuNPs) produced from Gelidiella acerosa, marine algae using green synthesis method was evaluated for its antidiabetic, antibacterial and antioxidant activity. Well-developed GA-AuNPs were effectively characterized using advanced analytical instruments like HRTEM, UV-visible, SEM and XRD. This analysis exposed GA-AuNPs to be present with spherical, hexagonal structure and crystalline nature. The average size of GA-AuNPs particles was estimated to lie between $5.81 \mathrm{~nm}$ to $117.59 \mathrm{~nm}$ by using Debye-Scherer equation. The enzyme inhibitory property of $\left(\mathrm{IC}_{50}\right)$ of $\mathrm{G}$. acerosa aqueous extract and synthesized gold nanoparticles from $\mathrm{G}$. acerosa against a amylase and a- glucosidase enzyme was found to be $2.1 \pm 0.01,3.7 \pm 0.01 \mu \mathrm{g} / \mathrm{mL}$ and $2.8 \pm 0.02,4.1 \pm 0.01$, respectively. Further antioxidant assessment of GA-AuNPs were examined using DPPH and FRAP assays, the results exhibited that the strong antioxidant activity were observed in all the concentrations when compared with standard. Finally antibacterial activity was evaluated the GA-AuNPs against gram positive and gram negative bacteria, the strong antibacterial activity was observed in both the bacterial strains when compared with standard antibiotic. The GA-AuNPs from marine algae was exhibited to be strong inhibitory activity against alpha amylase and alpha glucosidase enzyme, antioxidant activity and antibacterial activity, these GA-AuNPs are projected to have potential biological applications.
\end{abstract}

Keywords Gelidiella acerosa · Gold nanoparticles · a-glucosidase inhibitory activity · Antioxidant activity · Antibacterial activity

\section{Introduction}

Gold nanoparticles (AuNPs) considerably shows attention because of its simplicity in preparation and extensive applications. They are being used as biocatalysts, disease diagnostic materials, in therapeutics and further recent times in nanomedicine [1-4]. Hence the production of biocompatible AuNPs synthesized using plant source with appropriate reactive groups have a great potential in nanomedicine $[5,6]$. Consideration to inhibition of a-glucosidase enzyme using AuNPs is major target and the increasing therapeutic specificity is new idea (Fig. 1).
Type II diabetes statistics is seriously increasing at a shocking rate, in 2014 an estimated 422 million people worldwide are affected with diabetes-a prevalence of $8.5 \%$ among the adult population [7]. Postprandial hyperglycemia is the major complications of type 2 diabetes patients and controlling postprandial blood glucose levels is particularly significant, since postprandial hyperglycemia is considered more dangerous than fasting blood glucose [8]. Digestive enzyme, a-glucosidase can release glucose by hydrolyzing starch rapidly, resulting in postprandial hyperglycemia to diabetic patients. Therefore, Identifying and describing the inhibitors of a-glucosidase various sources that can be used

P. Senthilkumar, senthilkumar1185@gmail.com | ${ }^{1}$ Department of Biotechnology, Kongunadu Arts and Science College, Coimbatore, Tamilnadu 641 029, India. ${ }^{2}$ Department of Biotechnology, PSG College of Arts and Science, Coimbatore, Tamilnadu, India. ${ }^{3}$ School of Biotechnology, Dr G R Damodaran College of Science, Coimbatore, Tamilnadu, India.

SN Applied Sciences (2019) 1:284 | https://doi.org/10.1007/s42452-019-0284-z

Received: 27 December 2018 / Accepted: 18 February 2019 / Published online: 1 March 2019 


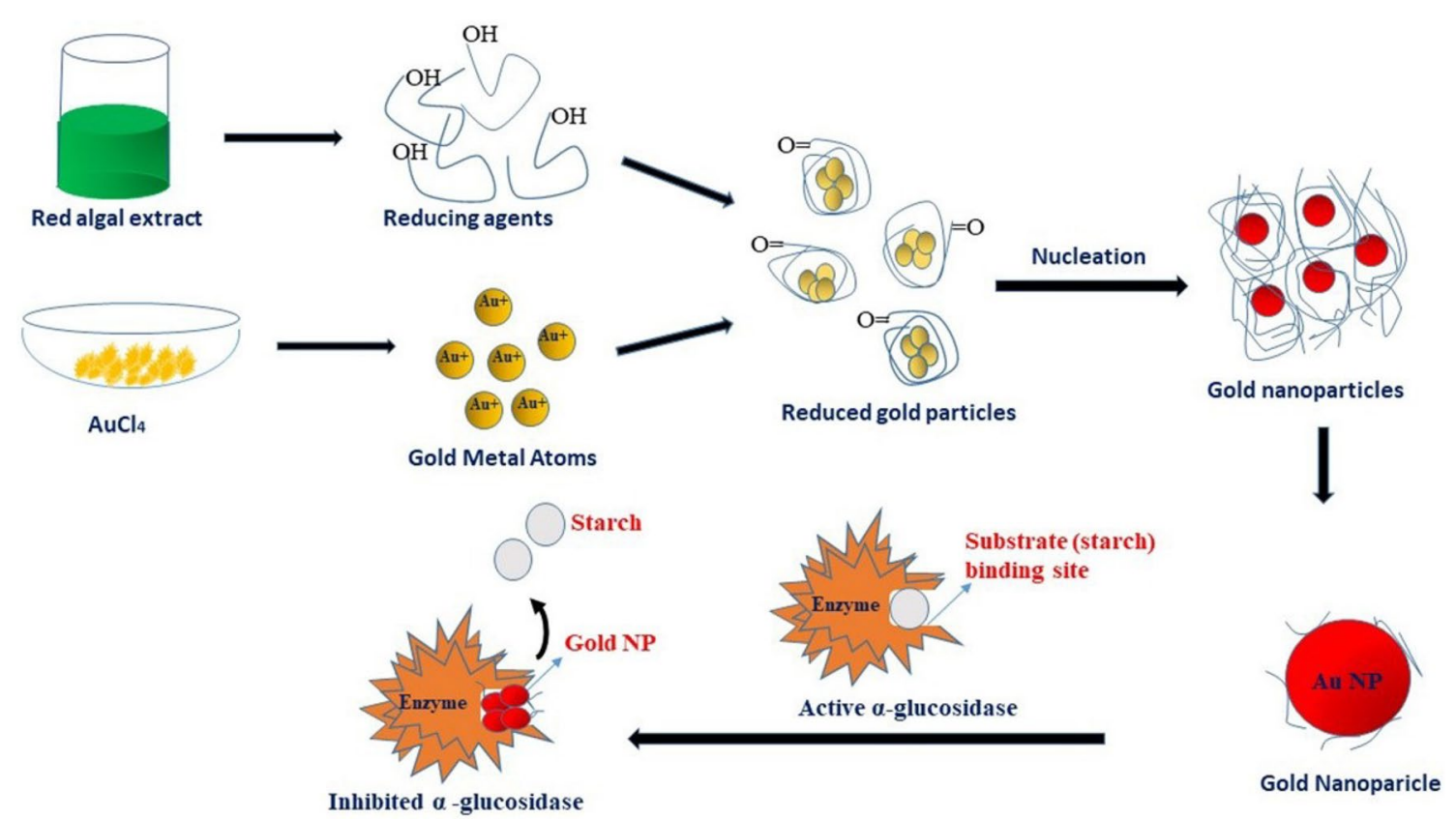

Fig. 1 Schimatic diagram of synthesis of GA-AuNPs and its alpha glucosidase enzyme inhibition property

significantly in medicine $[9,10]$. Application of metal nanoparticles in this fast-growing field has placed the source to the find the alternative methods to postprandial hyperglycemia. The recent scientific investigation have been reported that metal nanoparticles are being used for enzymolysis and enzyme inhibition assays [11].

Marine algae have received special attention as a source for the synthesis of nanoparticles $[12,13]$. The seaweed extracts possesses bioactive metabolites like flavonoids, phenols, citric acid, ascorbic acid, polyphenolic, terpenes, alkaloids and reductase could act as reducing agents [14]. The earlier research suggest that there are some marine algae which are very good biological material for the synthesis of nanoparticles [15-17]. Interestingly we had done our study previously in Gelidiella acerosa for the first time, it has been reported that the synthesis of highly stable Ag-NPs, characterization and its antimicrobial activity [18]. Also few of the research were conducted using this marine algae, $G$. acerosa possessed rich antioxidant property, [19] anticancer activity, [20], cytotoxicity and genotoxicity [21] and antibacterial activity [22].

Hence, in the present investigation, we have reported of the green synthesis of AuNPs using Gelidiella acerosa marine algal extract and the characterization properties have been confirmed by XRD, SEM, HRTEM, FTIR and UV analysis. The present study was focused on enzyme inhibitory, antibacterial and antioxidant efficacy of marine algae mediated Gold nanoparticles.

\section{Materials and methods}

\subsection{Materials}

Gold (III) chloride and P-nitrophenyl-a-glucopyranoside were purchased from Sigma-Aldrich Co. (St. Louis, MO, USA). Alpha-glucosidase, fetal bovine serum (FBS), and Dulbecco's modified eagle medium (DMEM) were obtained from HiMedia Laboratories (Mumbai, India). Acarbose was purchased from Bayer Scientific (Leverkusen, Germany). All other reagents and chemicals were of analytical grade and obtained locally Coimbatore.

\subsection{Marine algae collection}

Gelidiella acerosa (Forsskal), a red marine algae was collected from Mandapam coastal region $\left(78^{\circ} 8^{\prime} \mathrm{E}, 9^{\circ} 17^{\prime} \mathrm{N}\right)$ located in Gulf of Mannar, Tamilnadu, South India during the month of June 2017. The collected marine algal samples were instantly carefully washed with marine water to remove the unwanted fouling particles and then transported to laboratory with ice box and washed thoroughly with fresh water to remove epiphytic diatoms and adhering debris. Samples were further scrubbed by sterilized distilled water to remove the salted materials remaining on the external parts of the samples. After cleaning, the marine algae was dried in shade at room 
temperature for 2 weeks. The dried materials of all the marine algae were ground using the kitchen electric blender and the grounded powder material was used to synthesis of nanoparticles.

\subsection{Preparation of the extract}

Marine algal samples $(5 \mathrm{~g})$ were taken and boiled with sterilized distilled water $(100 \mathrm{~mL})$ and constantly stirred with glass rod under $60^{\circ} \mathrm{C}$ for $20 \mathrm{~min}$. The green-colored aqueous extract (GA-AE) was delivered to Whatman No. 1 filter paper, and the remains were kept at $4{ }^{\circ} \mathrm{C}$ for future study.

\subsection{Phytochemical analysis}

The preliminary phytochemical screening of GA-AE was done as per the standard method of [23].

\subsection{Synthesis of gold nanoparticles}

To the synthesis of gold nanoparticles (GA-AuNPs), $10 \mathrm{~mL}$ of aqueous GA-AE was mixed into $90 \mathrm{~mL}$ of $1 \mathrm{mM}$ aqueous solution of gold chloride $\left(\mathrm{HAuCl}_{4} \cdot 3 \mathrm{H}_{2} \mathrm{O}\right)$. After this, the solution was kept at $37^{\circ} \mathrm{C}$ under static condition. Instantaneously, a control was maintained without adding $\mathrm{HAuCl}_{4}$. The period of adding GA-AE solution into the gold metal ion solution is considered as the initial point of the synthesis reaction. After stirred at room temperature for $1 \mathrm{~h}$ under exposure to direct sun light, the light-yellow color of gold metal ion solution goes into ruby red color representing the formation of GA-AuNPs. The GA-AuNPs were washed with distilled water for three times by centrifugation at 10,000 rpm for 15 min, to eliminate any strand of unbound phyto constituents. The powdered GA-AuNPs were dried at $50{ }^{\circ} \mathrm{C}$ in a dry oven and stored at $4{ }^{\circ} \mathrm{C}$ till further use.

\subsection{Characterization of gold nanoparticles}

UV-Vis spectroscopy of the GA-AuNPs solution was done using a JASCO UV Vis NIR (V-670) within a range of 200-800 $\mathrm{nm}$. Fourier transform infrared spectrophotometer (FTIR) measurements of the GA-AuNPs were carried out using Shimadzu IR-Prestige-21 in the range of $400-4000 \mathrm{~cm}^{-1}$. Crystal structure of the GA-AuNPs was done by X-ray diffraction (XRD) technique using a Rigaku Miniflex diffractometer with CuKa radiation of wavelength $1.5418 \AA$ and filtered through the $\mathrm{Ni}$ absorber in the range $10^{\circ}$ to $90^{\circ}$, Phase identification was done using the standard XRD reference database. Scanning electron microscope (SEM) analysis were done to find out the surface morphology of nanomaterial using with JSM-5800LV, operating at $20 \mathrm{kV}$. The morphological characterization of the GA-AuNPs was done by high resolution transmission electron microscopy (HRTEM).

\subsection{In vitro a-amylase inhibitory activity}

The a-amylase inhibitory activity of GA-AuNPs was assessed according to the procedure of [24]. The reactant mixture contains $200 \mu \mathrm{L}$ of starch $\left(0.4 \mathrm{mg} \times \mathrm{mL}^{-1}\right)$ and $100 \mu \mathrm{L}$ with different concentrations ( $1 \mu \mathrm{g}$ to $5 \mu \mathrm{g} / \mathrm{mL}$ ) of GA-AE, GA-AuNPs and acarbose standard drug were dissolved in phosphate buffer $\left(20 \mathrm{mM} \mathrm{NaH}_{2} \mathrm{PO}_{4}\right.$ and $6.7 \mathrm{mM}$ $\mathrm{NaCl}, \mathrm{pH}$ 6.9). Consequently, $50 \mu \mathrm{L}$ of a-amylase solution prepared with phosphate buffer was added to the reactant mixture and the final volume was made up to $500 \mu \mathrm{L}$ with phosphate buffer solution. After that, the enzymatic reaction was allowed for 3 min at dark incubation condition at room temperature. After the incubation $1 \mathrm{~mL}$ of $0.1 \%$ hydrochloric acid was added to terminate the reaction. Then, few drops of iodine reagent were added to the reactant mixture. The a-amylase inhibitory activity was measured at $660 \mathrm{~nm}$ using a multi-well ELISA plate reader (Thermo fisher, India).

Percentage of inhibition(\%)

$$
=[(\text { control OD }- \text { test OD }) /(\text { control OD })] \times 100 .
$$

All experiments were performed in triplicate and error bars represent the SD.

\subsection{In vitro a-glucosidase inhibition assay}

To study the a-glucosidase inhibition effect of GA-AuNPs was carried out a modified method of [25]. In a 96 well plates, the stock solution of a-glucosidase $(0.5 \mathrm{U} / \mathrm{mL})$ was also prepared in $20 \mathrm{mmol} / \mathrm{L}$ sodium phosphate buffer ( $\mathrm{pH}$ 6.9). The a-glucosidase (7.5 IL) was mixed with different concentrations of GA-AE, GA-AuNPs and acarbose standard drug ( $1 \mu \mathrm{g}$ to $5 \mu \mathrm{g} / \mathrm{mL}$ ) respectively. The mixture was incubated of above at $37^{\circ} \mathrm{C}$ for $15 \mathrm{~min}, 100 \mu \mathrm{L}$ of $P$-nitrophenyl-a-glucopyranoside (PNPG) was added further. The reaction mixture was incubated for $10 \mathrm{~min}$ at $37^{\circ} \mathrm{C}$. To stop the reaction, $100 \mu \mathrm{L}$ of Sodium carbonate $\left(\mathrm{Na}_{2} \mathrm{CO}_{3}\right)(0.1 \mathrm{M})$ was added, the OD values measured at $405 \mathrm{~nm}$ in triplicate ELISA plate reader (Thermo Fisher Scientific, India). Acarbose alone was used as reference and controls for assay contain only PNPG and a-glucosidase without AuNPs or acarbose.

Percentage of inhibition(\%)

$$
=[(\text { control OD }- \text { test OD }) /(\text { control OD })] \times 100 .
$$

All experiments were performed in triplicate and error bars represent the SD. 


\subsection{DPPH radical scavenging assay}

DPPH radical scavenging activity of samples and ascorbic acid were performed according to the standard method [26]. In brief, $2 \mathrm{~mL}$ of GA-AE, GA-AuNPs and ascorbic acid at different concentrations ( $1 \mu \mathrm{g}$ to $5 \mu \mathrm{g} / \mathrm{mL}$ ) were incorporated with $1 \mathrm{~mL}$ of $0.1 \mathrm{mM} \mathrm{DPPH}$ solution. Then the reaction mixture was immediately shaken for a few seconds and incubated at dark condition for $30 \mathrm{~min}$. The OD values of the samples and control were recorded at $517 \mathrm{~nm}$.

\subsection{Ferric ion reducing power (FRAP) assay}

FRAP scavenging activity of GA-AE, GA-AuNPs was studied to the modified method of [27]. FRAP stock solution includes $20 \mathrm{mM}$ ferric chloride hexahydrate, $10 \mathrm{mM}$ TPTZ and $300 \mathrm{mM}$ acetate buffer ( $\mathrm{pH}$ 3.6) solution. The working standard solution of FRAP reagent was prepared by adding $4 \mathrm{~mL}$ of ferric chloride hexahydrate solution, $30 \mathrm{~mL}$ of acetate buffer and $4 \mathrm{~mL}$ of TPTZ solution. $500 \mu \mathrm{L}$ of different concentrations ( $1 \mu \mathrm{g}$ to $5 \mu \mathrm{g} / \mathrm{mL}$ ) of GA-AE, GA-AuNPs and ascorbic acid were mixed to the test tubes containing $2.5 \mathrm{~mL}$ of FRAP solution and incubated at dark condition for $30 \mathrm{~min}$. The OD value of the sample and ascorbic acid was taken at $593 \mathrm{~nm}$. Three replications were performed for the tested assay and statistical analysis was performed. The in vitro antioxidant and diabetic enzyme inhibitory activities of the samples were calculated using the following formula:

Inhibition $(\%)=\mathrm{A} 0-\mathrm{A} 1 \mathrm{~A} 0 \times 100$,

where $\mathrm{A} 0$ is absorbance of the control, $\mathrm{A} 1$ is absorbance of the sample. The inhibitory activity of samples and standards were expressed by the inhibitory concentration $\left(I C_{50}\right)$ values that were calculated using Graph pad prism version 5 (California, USA).

\subsection{Antibacterial activity}

The antibacterial activities of the GA-AuNPs were evaluated by the agar well diffusion method [16]. Briefly, a series of sterile Nutrient agar media plates were swabbed with $100 \mu \mathrm{L}$ of overnight bacterial cultures of Escherichia coli (MTCC 443), Serratia marcescens (MTCC 97), Klebsiella pneumonia (MTCC 432) and Bacillus subtilis (MTCC 441) Cultures respectfully. The bacterial strains obtained from Institute of Microbial Technology, Chandigarh, were used for evaluating antimicrobial activity. Wells of $5 \mathrm{~mm}$ in diameter were made on agar plates using a well puncher. $20 \mu \mathrm{L}$ of green synthesized GA-AuNPs, GA-AE, $\mathrm{AuCl}_{3}$ solution and positive control (chloramphenicol) were injected into separate wells. The plates were incubated for $24 \mathrm{~h}$ at $37^{\circ} \mathrm{C}$ and the antimicrobial activity was evaluated by measuring the zone of inhibition around the wells.

\section{Results and discussion}

\subsection{Phytochemical screening}

The preliminary phytochemical screening of GA-AE exhibited the presence of alkaloids, flavonoids, saponins, phenolics, steroids and tannins were found to be present (Table 1). Various secondary metabolites were identified the GA-AE using preliminary phytochemical screening [22] which act as a reducing agent for the formation of GAAuNPs. GA-AuNPs were finally obtained, characterized and studied for antidiabetic and antioxidant analysis.

\subsection{Synthesis and UV-Vis spectrum of GA-AuNPs}

The GA-AuNPs were successfully synthesized using dried GA-AE and the chloroauric acid were reduced very quickly in the presence of secondary metabolites and it was determined by the color changes (Fig. 2a, b). The color of the solution turned pale yellow to ruby-red which approves the reduction of $\mathrm{Au}^{3+}$ to $\mathrm{Au}^{0}$ [28]. Under UV-visible spectroscopy, GA-AuNPs exposed surface plasmon resonance (SPR) with absorption bands at $\lambda=526 \mathrm{~nm}$ of $\mathrm{G}$. acerosa indicating the formation of gold nanoparticles. The UV-Vis was conducted after 3 months of synthesis of GA-AuNPs was compared with that data of GA-AuNPs synthesized initially. The Surface plasmon resonance with $\lambda \max 526$ remains almost same revealing of unaffected $\lambda$ max value, GA-AuNPs (Fig. 2). It suggests that the G. acerosa secondary metabolites plays a significant part in giving stability to GA-AuNPs. In the peak intensity at $500-550 \mathrm{~nm}$ of UV-Vis spectra exhibited steady increase which confirmed the growth and formation of GA-AuNPs and increase in the concentration of the metal ions exposed increase in particle size. The previous reports of AuNPs synthesis $[29,30]$

Table 1 Phytochemical screening of GA-AE

\begin{tabular}{ll}
\hline Phytochemicals & GA-AE \\
\hline Alkaloids & + \\
Flavonoids & + \\
Glycosides & - \\
Saponins & + \\
Phenolics & + \\
Steroids & + \\
Tannins & + \\
\hline
\end{tabular}

[+] Present

$[-]$ Absent 


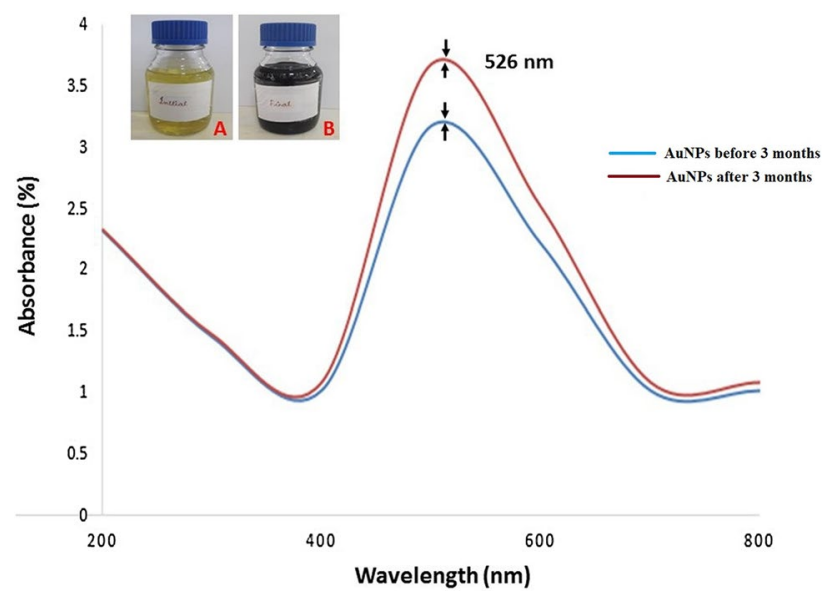

Fig. 2 UV-Vis absorption spectra of GA -AuNPs from G. acerosa green synthesis of GA-AuNPs and it shows unchanged SPR for GAAuNPs before and after 3 months of synthesis. a Initial photograph shows that containers with $\mathrm{Au}^{3+}$ ions in the concentration of $1 \mathrm{mM}$ with the color of pale yellow. $\mathbf{b}$ Photograph of green synthesized GA-AuNPs with the color of ruby-red which approves the reduction of $\mathrm{Au}^{3+}$ to $\mathrm{Au}^{0}$

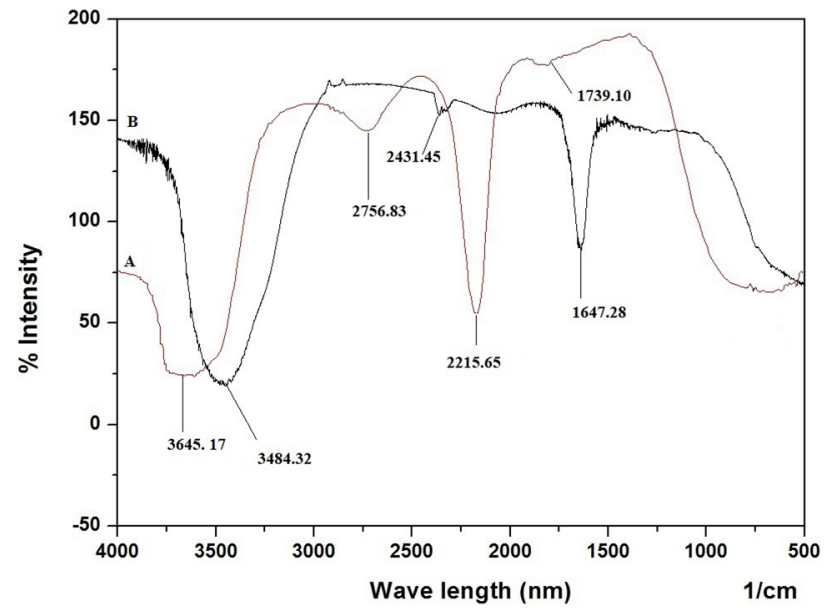

Fig. 3 FTIR spectra of GA-AE (a) and (b) GA-AuNPs nanoparticles range between 500 and $4000 \mathrm{~cm}^{-1}$

exhibited the strong peak at $540 \mathrm{~nm}$ after $12 \mathrm{~h}$ of incubation which was correlate with our study.

\subsection{FT-IR spectral analysis of GA-AuNPs}

The results of the FTIR spectral analysis of GA-AE and GAAuNPs data were showed in Fig. 3. The IR spectrum of the GA-AE band A exhibit the broad peak at $3645.17 \mathrm{~cm}^{-1}$, which is the characteristic of $-\mathrm{OH}$ stretching vibrations. Functional groups exhibited were aromatic group at $2756.83 \mathrm{~cm}^{-1}$ and the band at $2215.65 \mathrm{~cm}^{-1}$ corresponds to $\mathrm{C}=\mathrm{N}$ group and the small peak showed at $1739.10 \mathrm{~cm}^{-1}$ is responsible for $-\mathrm{C}-$ stretching vibration. The FTIR spectrum of GA-AuNPs, Fig. 3a showed, the absorbance peak at $3482.32 \mathrm{~cm}^{-1}$ is corresponds to $\mathrm{O}-\mathrm{H}$ group, the peak intensity reduced after capping the nanoparticles. Aldehyde group at 2431.45 and the band at $1647.28 \mathrm{~cm}^{-1}$ associated to the $\mathrm{C}=\mathrm{O}$ stretching vibration of the amide band I band [31]. The capping and stability character of GA-AuNPs may be because of these phytochemicals present in the GA-AE [22].

\subsection{XRD analysis of GA-AuNPs}

The crystalline structure of the synthesized GA-AuNPs can be showed using X-ray diffraction profile (Fig. 4a). A display major characterization peaks at around interplanar spacing of $0.21 \mathrm{~nm}$ corresponding to the (111) planes of the face centered cubic (fcc) GA-AuNPs, determining the development of polycrystalline GA-AuNPs. The experiential diffraction pattern of GA-AuNPs is consistent similar to the results reported earlier with standard JCPDS File No. 04-0784 [32]. The detected spectrum of the small diffraction peaks showed that the crystallization of bioorganic phase occurred on the surface of the nanoparticles [33, 34] the crystallite size of the GA-AuNPs was calculated by the Debye-Scherrer equation [35].

\subsection{SEM analysis of GA-AuNPs}

Figure 5 shown the surface morphology of green synthesized GA-AuNPs were determined using scanning electron microscope (SEM) analysis. The results obtained from SEM analysis reveal numerous spherical, hexagonal and cubical nanoparticles with aggregation due to the reduction of gold ions. Our study results correlate with the study of [36] from the scanning electron microscopy images found that biological synthesis of GA-AuNPs has a uniform and spherical, hexagonal and cubical shape.

\subsection{HRTEM-SAED analysis of GA-AuNPs}

The size and shape of the green synthesized GA-AuNPs were measured analyzed with the High-resolution transmission electron microscope (HRTEM) (Fig. 6a and c). The obtained HRTEM image exposed that the green synthesized GA-AuNPs are controlled uniform in size with the particles are spherical in shape with less agglomeration. The resulted particles average size varying from 5.81 to $117.59 \mathrm{~nm}$ (Fig. $6 \mathrm{~b}$ and d). This is reasonable to conclude that the marine algal extract encompasses metabolites that avoid the accumulation of the GA-AuNPs. The previous studies states that the Pectin mediated gold nanoparticles, exhibited spherical in shape in the range of $8 \mathrm{~nm}$ [37]. Selected area electron diffraction (SAED) pattern of 


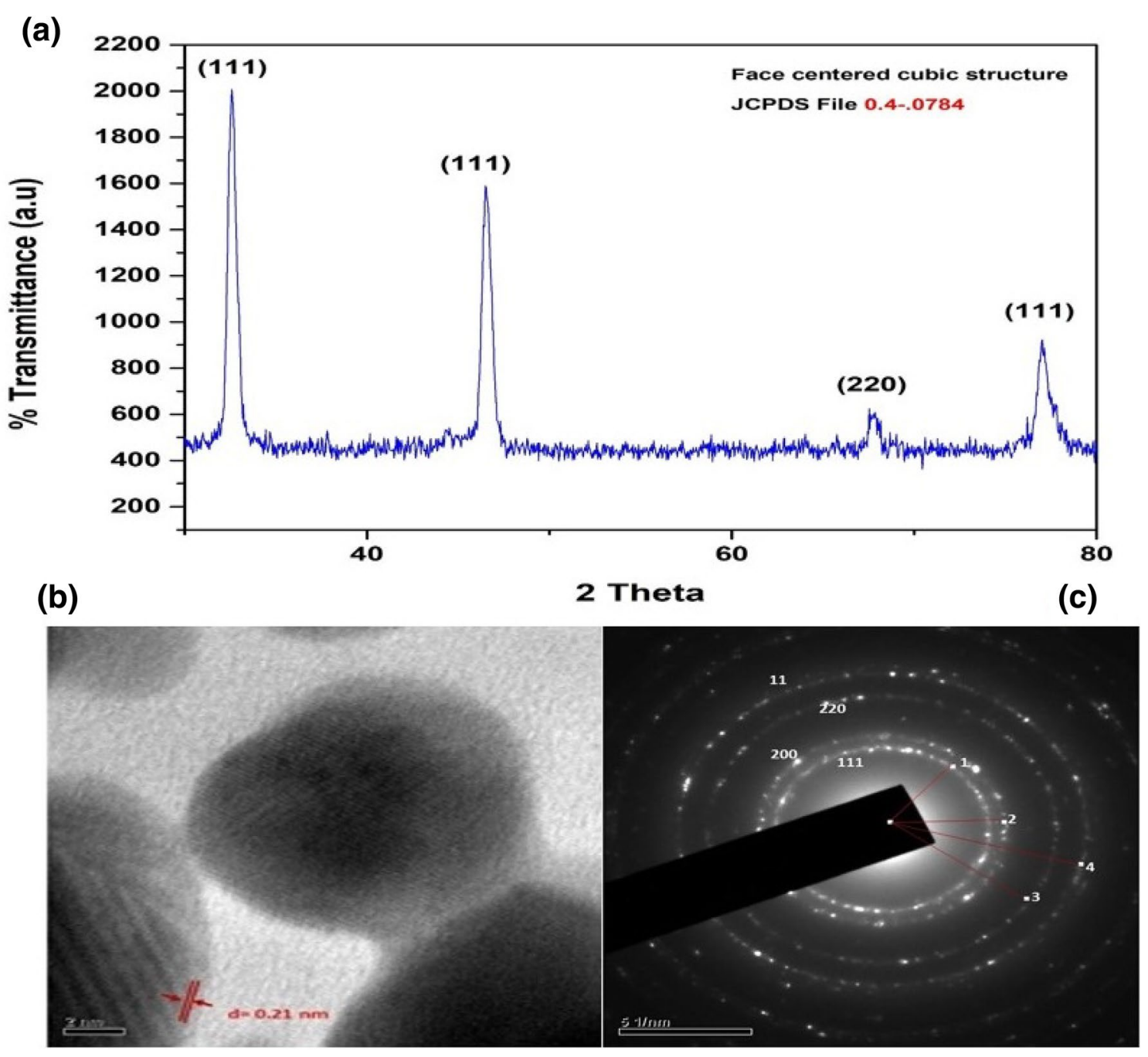

Fig. 4 X-ray diffraction pattern and electron microscopic analysis of nanoparticle systems. a Characteristic XRD pattern of GA-AuNPs resulting the signature peaks, b HRTEM photograph $(2 \mathrm{~nm})$ and

GA-AuNPs exposed poly-nanocrystalline structure. The SAED diffraction rings of GA-AuNPs results exhibited in good agreement with the X-ray diffraction (Fig. 4c). In the present analysis the crystalline structure of the GA-AuNPs is further evidenced by the SAED pattern with bright circular spots corresponding to (111), (200), (220), (311) and (222) Bragg reflection planes [38].

\subsection{Alpha-amylase inhibitory activity}

The human salivary alpha-amylase enzyme can be broken down to the complex starch molecules to simple glucose. Hence, the inhibition of alpha amylase enzyme could control the carbohydrate metabolism which also decreases the amount of glucose absorption. In the present study the observed inhibitory percentage of alpha amylase by GA-AE and GA-AuNPs are shown in Fig. 7a. The alpha showed the interplanar spacing (0.21 A) corresponding to the (111) planes of the face centered cubic (FCC) GA-AuNPs, c selected area electron diffraction (SAED) pattern of GA-AuNPs from G. acerosa

amylase inhibitory activity of GA-AuNPs exhibited highest inhibitory activity when compared to GA-AE with the $\mathrm{IC}_{50}$ values of $2.1 \pm 0.01$ and $3.7 \pm 0.01$, respectively. The positive control acarbose has revealed the potent $\alpha$-amylase inhibitory activity with the $I C_{50}$ value of $1.7 \pm 0.02$. The previous reports suggests that the marine algal compounds having the ability to inhibit alpha amylase enzyme [39].

\subsection{In vitro alpha-glucosidase Inhibition}

Inhibition of starch blocking enzyme a-glucosidase is a vital target to control a sudden increase of blood glucose. In this present study we studied GA-AuNPs, GA-AE alone and standard drug acarbose with different concentrations. The reaction scheme of AuNPs inhibition of alpha glucosidase inhibition shown in Fig. 1. The obtained results of the study exhibit the a-glucosidase

\section{SN Applied Sciences}



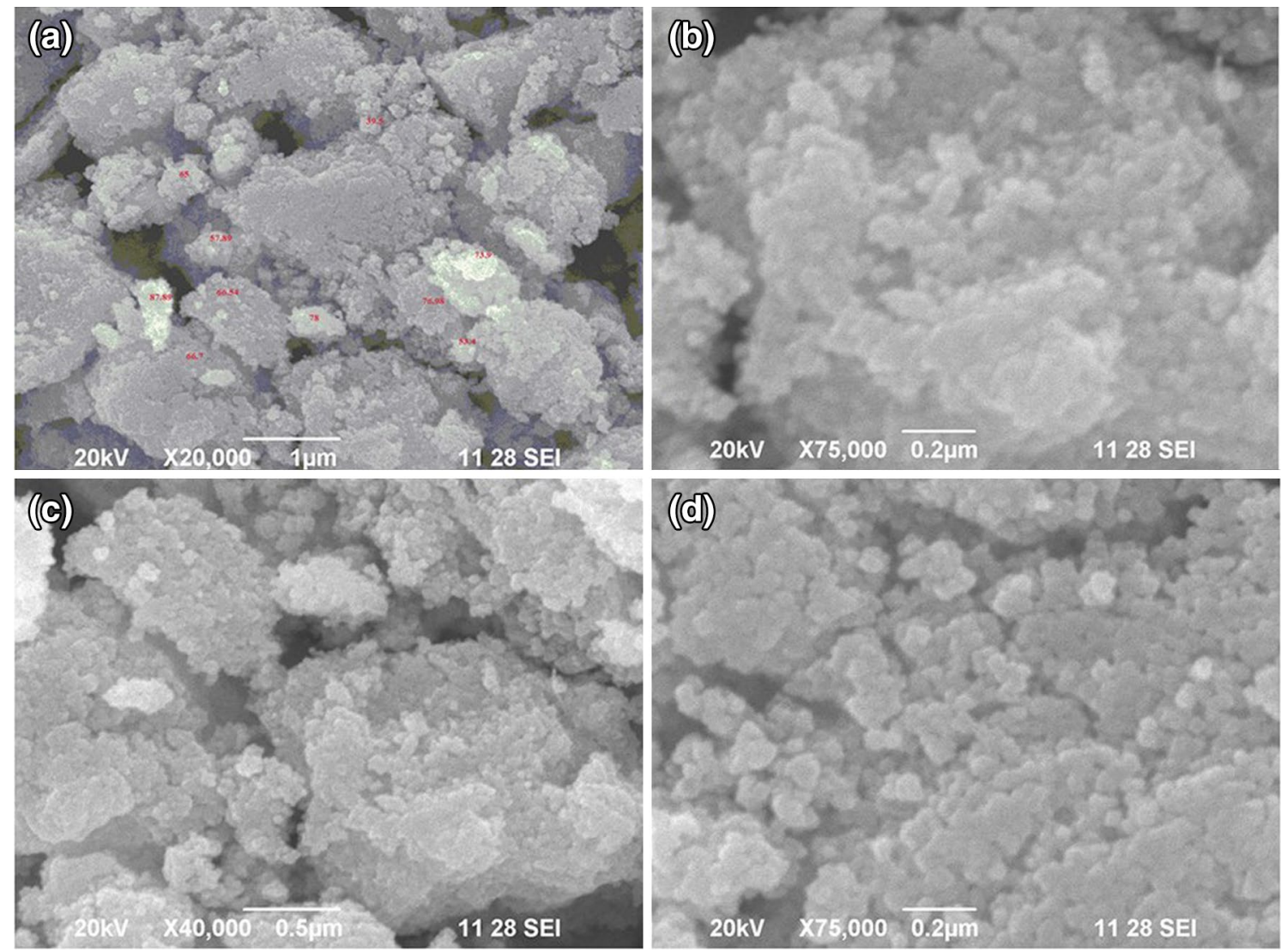

Fig. 5 SEM micrograph of GA-AuNPs from G. acerosa. The scale bars corresponds to $0.2 \mu \mathrm{m}, 0.5 \mu \mathrm{m}$ and $1 \mu \mathrm{m}$

enzyme inhibition was observed in an increasing order (Fig. 7b). As predictable, GA-AE extract exhibited the highest $\mathrm{IC}_{50}(4.1 \pm 0.01 \mu \mathrm{g} / \mathrm{mL})$, showing its relative effectiveness as a glucosidase inhibitor. Acarbose standard drug also was a strong inhibitor of a-glucosidase, exhibiting an $\mathrm{IC}_{50}(2.5 \pm 0.01 \mu \mathrm{g} / \mathrm{mL})$ that was lower than that of GA-AE.

Interestingly, the $\mathrm{IC}_{50}$ for GA-AuNPs $(2.8 \pm 0.02 \mu \mathrm{g} / \mathrm{mL})$ was slightly lower than the acarbose, this change was statistically significant. It is possible that at the higher concentrations of GA-AuNPs undergo aggregation, thereby lowers their inhibition activity. The concentration dependent reduction is being revealed in the percentage inhibition of alpha-glucosidase activity at $5,4,3,2$ and $1 \mu \mathrm{g} / \mathrm{mL}$ concentration of GA-AuNPs. The interaction of GA-AuNPs with these catalytic motifs in the present nanoparticles may alter the catalytic action of a-glucosidase and ultimately delays the development of glucose from the starch molecules. The major credit to alpha-glucosidase inhibitors are decrease in both postprandial glycemic levels and the total range of postprandial glucose levels. Metal nanoparticles are already proven as alpha-glucosidase inhibitors $[40,41]$.

\subsection{DPPH radical scavenging assay}

The DPPH radical scavenging activity of GA-AE and GAAuNPs was compared with the control, ascorbic acid The $\mathrm{IC}_{50}$ values of GA-AE, GA-AuNPs and ascorbic acid were: $3.6 \pm 0.01,2.9 \pm 0.01$ and $2.6 \pm 0.01 \mu \mathrm{g} / \mathrm{mL}$, respectively (Fig. 7c). The previous research results have revealed that marine algae possess strong natural antioxidant compounds [42]. The antioxidant molecules from marine algae are protected against oxidative stress due to risky environmental conditions and nanoparticle synthesized from marine algae exhibited good inhibitory activity on DPPH free radical. During the synthesis of the GA-AuNPs, marine algal compounds are adsorbed on the surface of the nanoparticles and considering the presence of high surface area to volume ratio, it appeared that these GAAuNPs, showed a high affinity to interact with and reduce DPPH free radical.

\subsection{FRAP assay}

In FRAP assay, the antioxidant capacity of GA-AuNPs reduced ferric (III) to ferrous (II) in a redox reaction that 

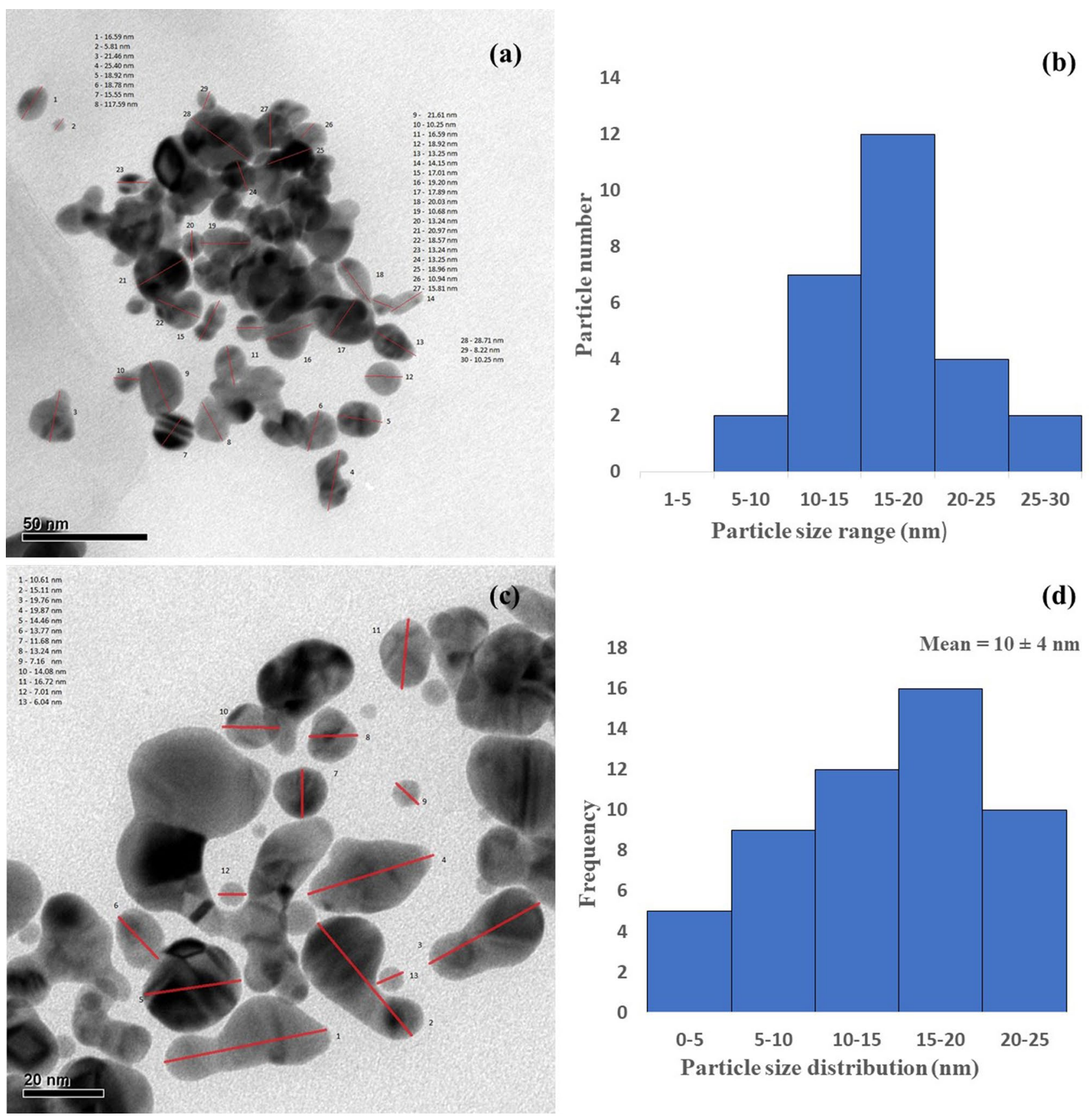

(d)

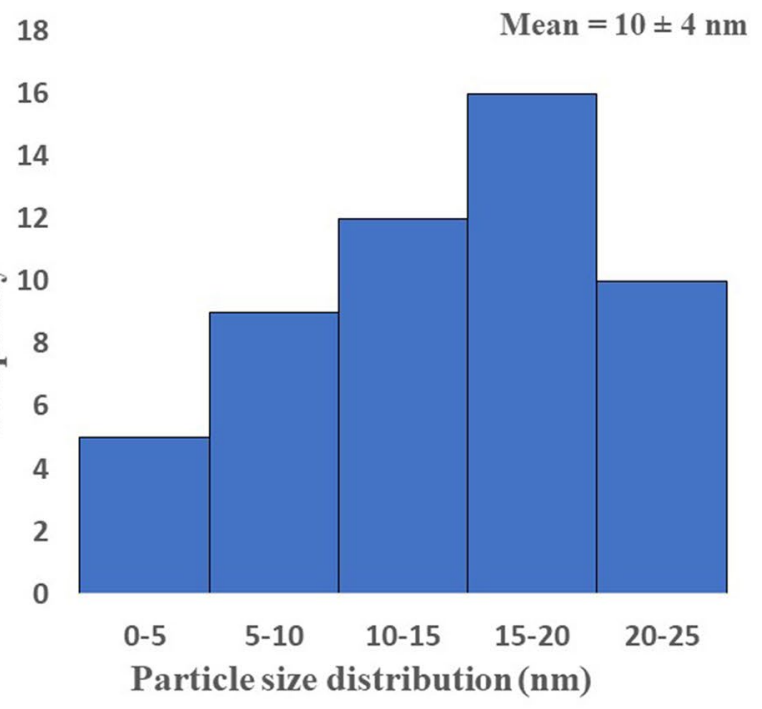

Fig. 6 High resolution transmission electron microscopic micrograph: a and c GA-AuNPs 50, $20 \mathrm{~nm}$ scale bar, $\mathbf{b}$ and $\mathbf{d}$ Histogram of AuNPs with particles size distribution (about 100 particles were counted)

involved electron transfer. The GA-AuNPs exhibited strong ferric reducing activity measured by FRAP assay (Fig. 7d) Among the various concentrations (1-5 $\mu \mathrm{g} / \mathrm{mL})$ tested, IC 50 values of GA-AE, GA-AuNPs and ascorbic acid were: $3.7 \pm 0.02,3.1 \pm 0.01$ and $2.3 \pm 0.02$, respectively. GAAuNPs slightly lowered the inhibition when compared with standard ascorbic acid. The resent research revealed that biosynthesized GA-AuNPs resulted in highest ferric reducing capacity [43]. Interestingly in our study, the green synthesized GA-AuNPs from GA-AE showed increased FRAP activity.

\subsection{Antibacterial activity}

The antimicrobial activity of the green synthesized GA-AuNPs was evaluated by the agar well diffusion method against pathogenic bacteria including grampositive and gram-negative (Fig. 8). The zone of inhibition 

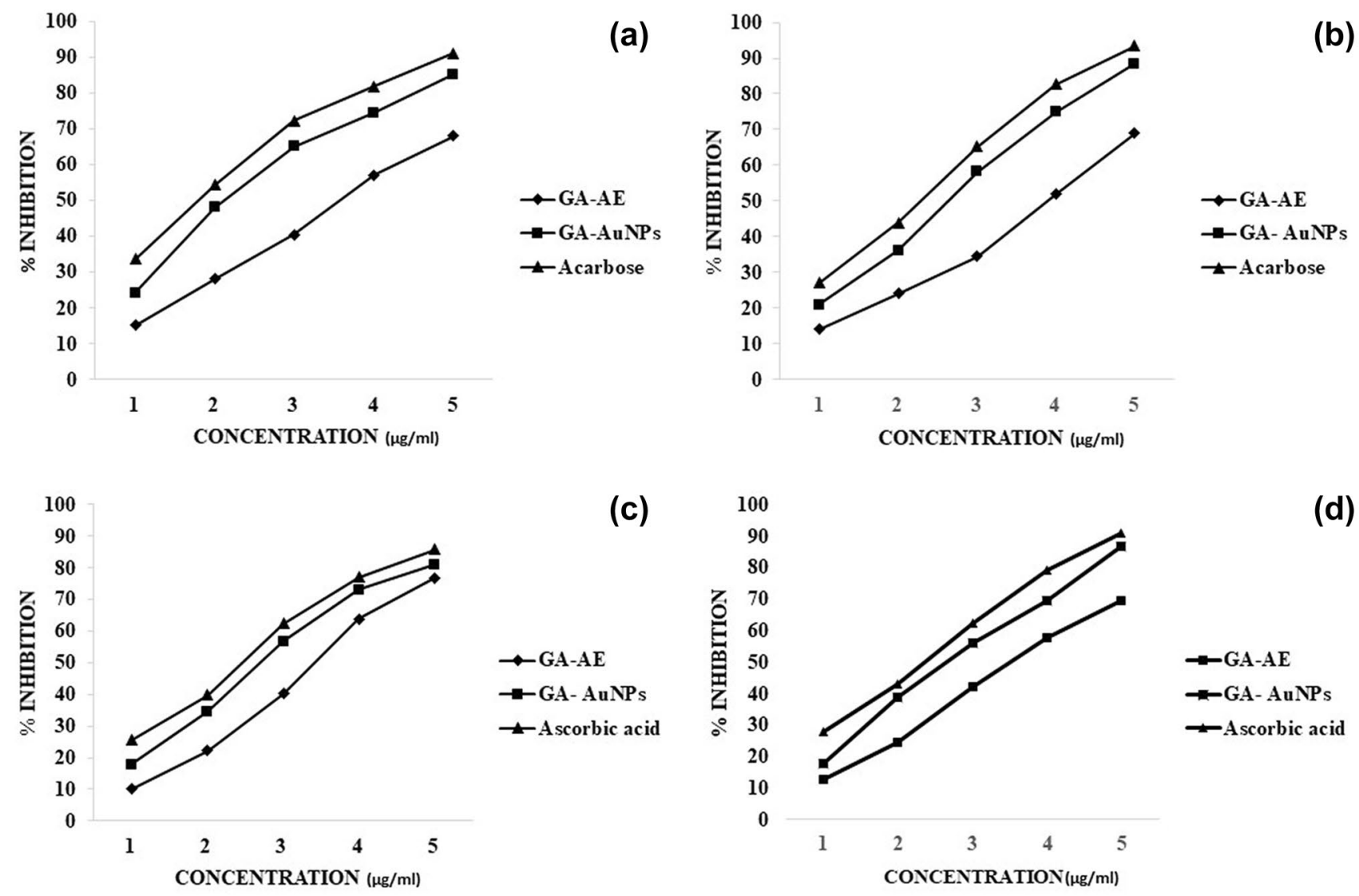

Fig. 7 Invitro antidiabetic and antioxidant activity, a, b In-vitro a-amylase and a-glucosidase inhibition activity of GA-AE, GAAuNPs and Acarbose. c, d In vitro antioxidant activity of GA-AE,

GA-AuNPs and ascorbic acid. The $\mathrm{IC}_{50}$ values were calculated using graph pad prism software
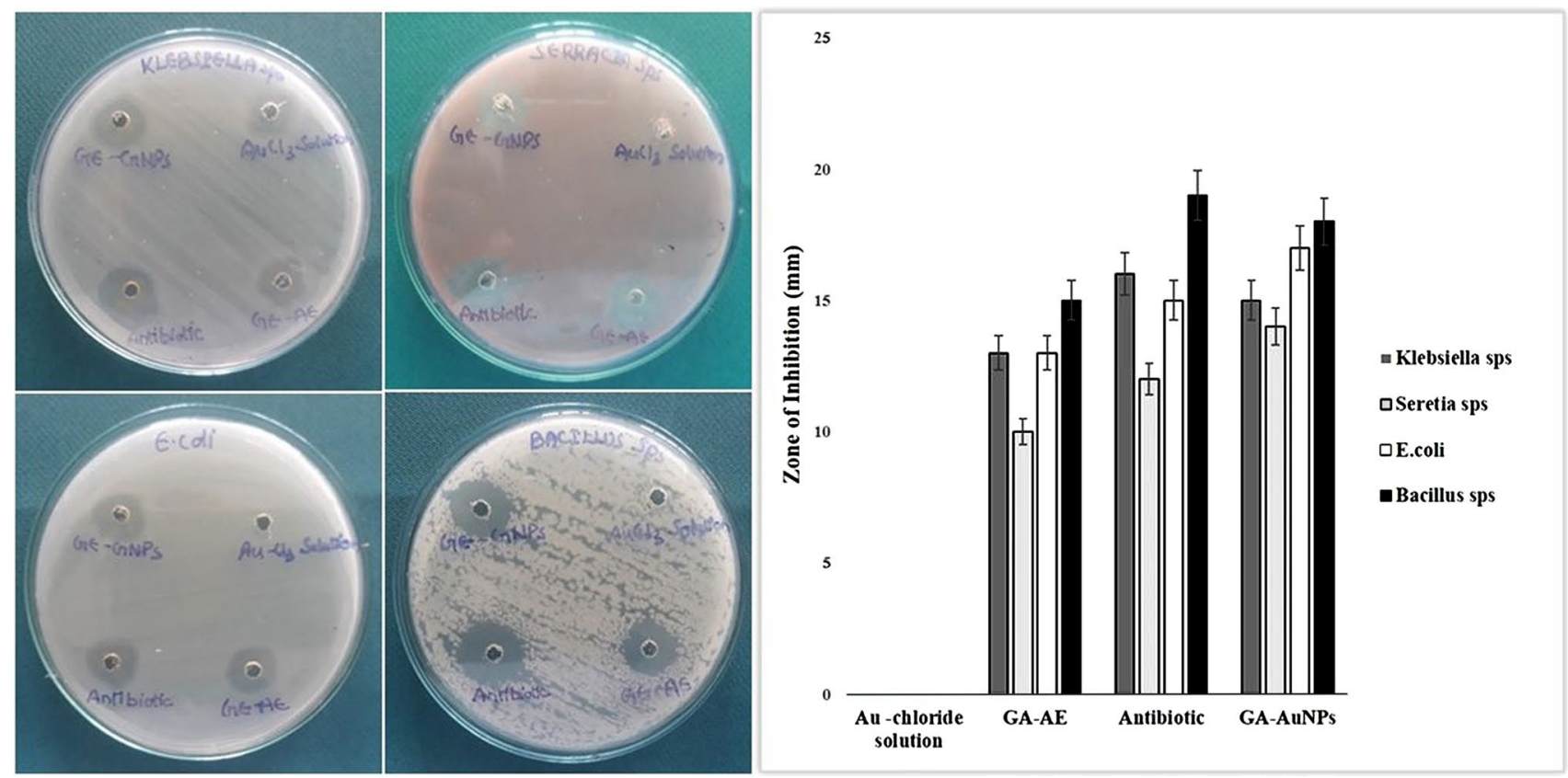

Fig. 8 Antibacterial activity of GA-AE, GA-AuNPs and control against (a), Klebsiella species (b), Seretia species (c), E. coli (d), Bacillus species. A bar graph showing antibacterial activity of GA-AuNPs against various bacterial pathogens 
Table 2 Inhibitory potential $\left(\mathrm{IC}_{50}\right)$ of the different samples $(\mu \mathrm{g} / \mathrm{mL})$

\begin{tabular}{lllll}
\hline Samples & $\begin{array}{l}\text { a-amylase inhibition } \\
\text { activity }\end{array}$ & $\begin{array}{l}\text { a-glucosidase inhibi- } \\
\text { tion activity }\end{array}$ & $\begin{array}{l}\text { DPPH radical scaveng- } \\
\text { ing activity }\end{array}$ & FRAP assay \\
\hline GA-AE & $3.7 \pm 0.01$ & $4.1 \pm 0.01$ & $3.6 \pm 0.01$ & $3.7 \pm 0.02$ \\
GA-AuNPs & $2.1 \pm 0.01$ & $2.8 \pm 0.02$ & $2.9 \pm 0.01$ & $3.1 \pm 0.01$ \\
Acarbose & $1.7 \pm 0.02$ & $2.5 \pm 0.01$ & - & - \\
Ascorbic acid & - & - & $2.6 \pm 0.01$ & $2.3 \pm 0.02$ \\
\hline
\end{tabular}

Inhibitory activity (mean $\pm \mathrm{SEM}, n=3$ ) of acarbose, ascorbic acid, GA-AE, GA-AuNPs measurements was given in Table 2 for agar well diffusion method. GA-AuNPs synthesized from marine algae exhibited strong activity against all tested bacterial strains. The maximal antibacterial activity of GA-AuNPs was found against Bacillus subtilis, followed by E. coli, Serratia marcescens and Klebsiella pneumonia. There is no inhibition found against all bacteria using negative control. The activity was relatively moderate for the treatment with GA-AE in all the gram positive and gram negative bacteria this is may be due to the presence of bioactive compounds present in the extract [22].

The antibacterial activity of green synthesized gold nanoparticles against gram positive and gram negative bacteria including human pathogenic organism can either be by intercellular and extracellular interaction [44]. The most suggested machinery for antibacterial activity of the gold nanoparticles is by the oxidative stress on the microbial cell [45] leading to the formation of extracellular vacuole using the intracellular enzyme lactate dehydrogenase. This improved activity primes the loss and damage of cell membrane integrity [46]. Thus the gold nanoparticles shows high scope as an active antimicrobial agent in medicine. This interesting nature of the gold nanoparticles will be studied in our future work addressing its genomic and proteomic interaction with microbes.

\section{Conclusions}

In conclusion, The GA-AuNPs were successfully synthesized using marine algae $G$. aceros $a$ and characterized with using UV, FTIR, XRD, SEM and HRTEM instruments. Green synthesized GA-AuNPs showed significant inhibition activity of a-glucosidase a-amylase very similar to acarbose drug being used presently for type II diabetes. The GAAuNPs exhibited the strong antioxidant activity. The established gold nanoparticles denote very good ecofriendly materials in the field of biomedicine, for which the initial research proposes them to be the potential drug, which could response the existing standard drug. Further, these nanoparticles desired to be explored in vivo animal system as regard to their toxicity, side effects of several other biochemical present in the living body environment prior to their usage. They also possess good antimicrobial activity against gram positive and gram negative bacteria and is highly efficient against Bacillus and E. coli. To the best of our knowledge this is the first report showing the potential effect of GA-AuNPs synthesized from marine algae G. acerosa and its inhibition activity for a-glucosidase, a-amylase and antioxidant activity, hence we are suggesting green synthesized GA-AuNPs potentially an active drug for postprandial hyperglycemia and the control of type II diabetes also the antibacterial and antioxidant material.

Acknowledgements The author (Dr. P. Senthilkumar) would like to thank UGC, India for the financial support through the minor research Project F. No.: 4-4/2015-16 (MRP/UGC-SERO). The authors are also grateful to the authorities of Kongunadu Arts and Science College, Coimbatore, Tamilnadu, India for providing facilities and for their encouragement. The authors would like to acknowledge Department of Nano Science and Technology, Karunya University for the XRD, SEM and FTIR analysis. We extend our thanks to Dr. Anuradha Ashok, Nanotech Research Facility, PSG Institute of Advanced Studies, Tamil Nadu, India for the HRTEM analysis.

\section{Compliance with ethical standards}

Conflict of interest The authors declare that they have no competing interests.

\section{References}

1. Niemey CM (2001) Nanoparticles, proteins, and nucleic acids: biotechnology meets materials science. Angew Chem Int Ed Engl 40(22):4128-4158

2. Huang SH (2006) Gold nanoparticle-based immune chromatographic test for identification of Staphylococcus aureus from clinical specimens. Clin Chim Acta 373(1-2):139-143

3. Xi D, Luo X, Ning Q, Lu Q, Yao K, Liu Z (2007) The detection of HBV DNA with gold nanoparticle gene probes. J Nanjing Med Univ 21(4):207-212

4. Lin CA, Yang TY, Lee $\mathrm{CH}$, Huang $\mathrm{SH}$, Sperling RA, Zanella $\mathrm{M}$, Li JK, Shen JL, Wang HH, Yeh HI, Parak WJ (2009) Synthesis, characterization, and bioconjugation of fluorescent gold nanoclusters toward biological labeling applications. ACS Nano 3(2):395-401

5. Iravani S (2011) Green synthesis of metal nanoparticles using plants. Green Chem 13(10):2638-2650 
6. Das RK, Brar SK (2013) Plant mediated green synthesis: modified approaches. Nanoscale 5(21):10155-10162

7. WHO Mortality Database (online database) (2016). Geneva: World Health Organization. http://apps.who.int/healthinfo/stati stics/mortality/causeofdeathquery/. Accessed 12 Jan

8. Xiao-Ping $Y$, Chun-Qing S, Ping Y, Ren-Gang M (2010) a-Glucosidase and a-amylase inhibitory activity of common constituents from traditional Chinese medicine used for diabetes mellitus. Chin J Nat Med 8(5):349-352

9. Kumar VG, Gokavarapu SD, Rajeswari A, Dhas TS, Karthick V, Kapadia Z, Sinha S (2011) Facile green synthesis of gold nanoparticles using leaf extract of antidiabetic potent Cassia auriculate. Colloids Surf B Biointerfaces 87(1):159-163

10. Venkatachalam M, Govindaraju K, Sadiq AM, Tamilselvan S, Kumar VG, Singaravelu G (2013) Functionalization of gold nanoparticles as antidiabetic nanomaterial. Spectrochim Acta A Mol Biomol Spectrosc 116:331-338

11. Wang S, Su P, Huang J (2013) Magnetic nanoparticles coated with immobilized alkaline phosphatase for enzymolysis and enzyme inhibition assays. J Mater Chem 1(12):1749-1754

12. US Natl Inst Heath (2012) Daily Med: current medical information. http://dialymed.nlm.nih.gov/dailymed/about.cfm

13. Kannan RR, Stirk WA, Van Staden J (2013) Synthesis of silver nanoparticles using the seaweed Codium capitatum PC Silva (Chlorophyceae). S Afr J botany 86:1-4

14. Santhoshkumar J, Rajeshkumar S, Kumar SV (2017) Phytoassisted synthesis, characterization and applications of gold nanoparticles-a review. Biochem Biophy 11:46-57

15. Ajdari Z, Rahman H, Shameli K, Abdullah R, Abd Ghani M, Yeap S, Abbasiliasi S, Ajdari D, Ariff A (2016) Novel gold nanoparticles reduced by Sargassum glaucescens: preparation, characterization and anticancer activity. Molecules 21(3):123

16. Deepak P, Sowmiya R, Ramkumar R, Balasubramani G, Aiswarya D, Perumal P (2017) Structural characterization and evaluation of mosquito-larvicidal property of silver nanoparticles synthesized from the seaweed, Turbinaria ornata (Turner) J. Agardh 1848. Artif. Cells Nanomed Biotech 45(5):990-998

17. Ramkumar VS, Pugazhendhi A, Prakash S, Ahila NK, Vinoj G, Selvam S, Kumar G, Kannapiran E, Rajendran RB (2017) Synthesis of platinum nanoparticles using seaweed Padina gymnospora and their catalytic activity as PVP/PtNPs nanocomposite towards biological applications. Biomed Pharmacother 92:479-490

18. SenthilKumar P, Sudha S (2011) Evaluation of alpha-amylase and alpha-glucosidase inhibitory properties of selected seaweeds from Gulf of Mannar. Int Res J Pharma 3:128-130

19. Vivek M, Kumar PS, Steffi S, Sudha S (2011) Biogenic silver nanoparticles by Gelidiella acerosa extract and their antifungal effects. Avicenna J Med Biotechnol 3(3):143

20. Suganthy N, Nisha SA, Pandian SK, Devi KP (2013) Evaluation of Gelidiella acerosa, the red algae inhabiting South Indian coastal area for antioxidant and metal chelating potential. Biomed Prev Nut 3(4):399-406

21. Lakmal HC, Samarakoon KW, Lee W, Lee JH, Abeytunga DT, Lee HS, Jeon YJ (2014) Anticancer and antioxidant effects of selected Sri Lankan marine algae. J Natl Sci Foun 42(4):315-323

22. Syad AN, Shunmugiah KP, Kasi PD (2012) Assessment of anticholinesterase activity of Gelidiella acerosa: implications for its therapeutic potential against Alzheimer's disease. Evid Based Compl Alt Med 2012:1-8

23. Harbone JB (1973) Phytochemical methods. Chapman and Hall, New York, pp 1-286

24. Matsui T, Tanaka T, Tamura S, Toshima A, Tamaya K, Miyata Y, Tanaka K, Matsumoto K (2007) a-Glucosidase inhibitory profile of catechins and theaflavins. J Agri Food Chem 55(1):99-105

25. Sheliya MA, Begum R, Pillai KK, Aeri V, Mir SR, Ali A, Sharma $M(2016)$ In vitro a-glucosidase and a-amylase inhibition by aqueous, hydroalcoholic, and alcoholic extract of Euphorbia hirta L. Drug Dev Ther 7:26

26. Adeosun AM, Oni SO, Ighodaro OM, Durosinlorun $\mathrm{OH}$, Oyedele OM (2016) Phytochemical, minerals and free radical scavenging profiles of Phoenix dactilyfera L. seed extract. Taibah Univ Med Sci 11(1):1-6

27. Adedayo BC, Oboh G, Oyeleye SI, Ejakpovi II, Boligon AA, Athayde ML (2015) Blanching alters the phenolic constituents and in vitro antioxidant and anticholinesterases properties of fireweed (Crassocephalum crepidioides). J Taibah Univ Medical Sci 10(4):419-426

28. Nadagouda MN, Hoag G, Collins J, Varma RS (2009) Green synthesis of Au nanostructures at room temperature using biodegradable plant surfactants. Cryst Growth Des 9(11):4979-4983

29. Kumar SA, Peter YA, Nadeau JL (2009) Facile biosynthesis, separation and conjugation of gold nanoparticles to doxorubicin. Nanotechnology 19(49):95-101

30. Dubey SP, Lahtinen M, Särkkä H, Sillanpää M (2010) Bioprospective of Sorbus aucuparia leaf extract in development of silver and gold nanocolloids. Colloids Surf B Biointerfaces 80(1):26-33

31. Coman C, Leopold LF, Rugină OD, Barbu-Tudoran L, Leopold N, Tofană M, Socaciu C (2014) Green synthesis of gold nanoparticles by Allium sativum extract and their assessment as SERS substrate. J Nanopart Res 16(1):2158

32. Karthicka V, Ganesh Kumara V, Maiyalaganb T, Deepaa R, Govindarajua K, Rajeswaria A, Stalin Dhasa T (2102) Green synthesis of well dispersed nanoparticles using leaf extract of medicinally useful Adhatoda vasica Nees. Micro and Nanosystems 4:192-198

33. Narayanan KB, Sakthivel N (2008) Coriander leaf mediated biosynthesis of gold nanoparticles. Mater Lett 62(30):4588-4590

34. Suresh R, Ponnuswamy V, Mariappan R (2013) Effect of annealing temperature on the microstructural, optical and electrical properties of $\mathrm{CeO}_{2}$ nanoparticles by chemical precipitation method. App Surf Sci 273:457-464

35. Surendra TV, Roopan SM (2016) Photocatalytic and antibacterial properties of phytosynthesized $\mathrm{CeO}_{2} \mathrm{NPs}$ using Moringa oleifera peel extract. J Photochem Photobiol, B 161:122-128

36. Song JY, Jang HK, Kim BS (2009) Biological synthesis of gold nanoparticles using Magnolia kobus and Diopyros kaki leaf extracts. Proce Biochemistry 44(10):1133-1138

37. Suganya KSU, Govindaraju K, Ganesh Kumar V, Karthick V, Parthasarathy K (2016) Pectin mediated gold nanoparticles induces apoptosis in mammary adenocarcinoma cell lines. Int J Biol Macromol. https://doi.org/10.1016/j.ijbiomac.2016.08.086

38. Dwivedi AD, Gopal K (2010) Biosynthesis of silver and gold nanoparticles using Chenopodium album leaf extract. Colloids Surf A Physicochem Eng Asp 369(1-3):27-33

39. Lordan S, Smyth TJ, Soler-Vila A, Stanton C, Ross RP (2013) The a-amylase and a-glucosidase inhibitory effects of Irish seaweed extracts. Food Chem 141(3):2170-2176

40. Kumar VG, Gokavarapu SD, Rajeswari A, Dhas TS, Karthick V, Kapadia Z, Shrestha T, Barathy IA, Roy A, Sinha S (2011) Facile green synthesis of gold nanoparticles using leaf extract of antidiabetic potent Cassia auriculata. Colloids Surf B 87(1):159

41. Senthilkumar P, Priya L, Kumar RS, Bhuvaneshwari DS (2015) Potent a-glucosidase inhibitory activity of green synthesized gold nanoparticles from the brown seaweed Padina boergesenii. Int. J Adv Multidiscip Res 2(11):0917-0923

42. Lee JH, Kim GH (2015) Evaluation of antioxidant activity of marine algae-extracts from Korea. J Aqua Food Product Technol 24(3):227-240

43. Madhanraj R, Eyini M, Balaji P (2017) Antioxidant assay of gold and silver nanoparticles from edible basidiomycetes mushroom fungi. Free Radicals and Antioxidants 7(2):137-142 
44. Mohamed MM, Fouad SA, Elshoky HA, Mohammed GM, Salaheldin TA (2017) Antibacterial effect of gold nanoparticles against Corynebacterium pseudotuberculosis. Int J Vet Sci Med 5(1):23-29

45. Li Y, Zhang W, Niu J, Chen Y (2012) Mechanism of photogenerated reactive oxygen species and correlation with the antibacterial properties of engineered metal-oxide nanoparticles. ACS Nano 6(6):5164-5173
46. Brewer M, Zhang T, Dong W, Rutherford M, Tian ZR (2007) Future approaches of nanomedicine in clinical science. Med Clin North Am 91(5):963-1016

Publisher's Note Springer Nature remains neutral with regard to jurisdictional claims in published maps and institutional affiliations. 